\title{
THE EFFECT OF HEMICELLULOSE EXTRACTION ON FIBER CHARGE PROPERTIES AND RETENTION BEHAVIOR OF KRAFT PULP FIBERS
}

\author{
Katja Lyytikäinen, ${ }^{\text {a,* }}$ Esa Saukkonen, ${ }^{\mathrm{b}}$ Isko Kajanto, ${ }^{\mathrm{b}}$ and Jari Käyhkö ${ }^{\mathrm{a}}$ \\ The integrated forest biorefinery (IFBR) concept provides a promising \\ opportunity for the development of the pulp and paper industry. One \\ proposed next generation technology for an integrated forest biorefinery \\ is the extraction of hemicelluloses, allowing the co-production of pulp and \\ different hemicellulose-based chemicals. In addition to paper properties, \\ hemicelluloses are known to be important for the function of cationic \\ papermaking additives, because they are the main source of charged \\ groups in fibers. This paper shows that the alkaline extraction of \\ hemicelluloses from bleached kraft pulp decreases both the total and \\ surface charge of the pulps. It was found that the decreased fiber charge \\ leads to increased filler retention with fixed retention aid dosage. The \\ reduction observed in the fiber surface charge for alkali-extracted pulp \\ was mainly attributed to the decrease in the amount of anionic groups \\ located in fines.
}

Keywords: Hemicelluloses; Alkaline extraction; Integrated biorefinery; Fiber charge; Filler, retention

Contact information: a: FiberLaboratory, Department of Chemical Engineering, Lappeenranta University of Technology, 57200, Savonlinna, Finland; b: Laboratory of Fiber and Paper Technology, Department of Chemical Engineering, Lappeenranta University of Technology, 53851, Lappeenranta, Finland,

*Corresponding author: katja.lyytikainen@lut.fi

\section{INTRODUCTION}

The conventional pulping processes only take a partial advantage from the wood material. A significant part of the material is dissolved during the cooking and bleaching stages and sent to the recovery cycle, where it is converted to energy through burning. However, the heating value of hemicelluloses is only about half of that for lignin (Vakkilainen 1999). From this point of view, it could be economically viable to convert the hemicellulose fraction to various value-added products, such as alcohols, carboxylic acids, lactones, and esters, just to mention a few (van Heiningen 2007).

Recently, several technologies for the removal of hemicelluloses from wood material prior to cooking have been under investigation (Al-Dajani and Tschirner 2008; Yoon et al. 2008; Mao et al. 2008). For hardwoods, one of the most promising fractionating technologies is the alkaline extraction, as it allows the recovery of xylan in nearly undegraded form, which is important for its usability in production of different chemicals (van Heiningen 2007). It is well known that pulping dissolves and degrades hemicelluloses, which end up in the black liquor where they are difficult to separate. In addition, it has been reported that by removing the hemicelluloses prior to cooking, the following pulping and bleaching stages will benefit. For example, less alkali may be

Lyytikäinen et al. (2011). "Hemicellulose, charge, retention," BioResources 6(1), 219-231. 219 
required for cooking to a certain kappa level, the rate of delignification may be increased, or the bleaching chemical consumption may be reduced (Amidon et al. 2006; Al-Dajani and Tschirner 2008; Yoon and van Heiningen 2008; Kautto et al. 2010).

The extraction of hemicelluloses from wood chips always yields an extraction product that is a mixture of the various compounds naturally present in wood. When an extraction product with higher purity is targeted, a similar type of extraction can be applied for a bleached pulp. It was recently reported that the extraction of bleached birch kraft pulp with strong alkali followed by precipitation or ultrafiltration yields an extraction product where $98-99 \%$ of the carbohydrates consist of xylan with a very narrow molar mass distribution. By this method, about 30 to $60 \%$ of the hemicelluloses originally present in wood can be removed in a relatively short time (Fuhrmann and Krogerus 2009; Talja et al. 2009).

In papermaking, the hemicelluloses are of great concern from many perspectives. Most importantly, they are the main constituents in the fiber cell wall that contribute to the electrostatic character of the fibers. In both softwoods and hardwoods, the fiber charge mainly originates from 4-O-methyl- $\alpha$-D-glucopyranosyluronic acids bound to the xylan backbone. An anionic charge is generated when these groups are ionized under prevailing conditions (Sjöström 1989). Thus, the removal of hemicelluloses from wood chips or bleached pulps can be expected to have a significant influence on the charge properties of the cellulosic fibers.

For the retention of cationic papermaking additives, the amount of charged groups located on the fiber surface or near the surface (so called subsurface) is most important. The strength of the fiber-fiber bonds and the paper tensile properties are also most affected by the surface charges. On the other hand, a number of charged groups in the fiber wall remain inaccessible, and some groups are only accessible to smaller molecules. The charged groups accessible to $\mathrm{Na}^{+}$are especially important for fiber swelling. (Sjöström 1989; Wågberg and Annergren 1997; Chen et al. 2005; Torgnysdotter and Wågberg 2003).

The purpose of the present study was to find out how the alkaline extraction of hemicelluloses from bleached kraft pulp affects fiber charge properties and retention behavior of the pulp.

\section{EXPERIMENTAL}

\section{Materials}

Chemicals

Polybrene and poly-diallyldimethylammonium chloride (p-DADMAC) were purchased from Sigma-Aldrich, Finland. Potassium polyvinyl sulfate (KPVS) was provided by Wako Pure Chemical Industries Ltd., Germany. Polybrene and KPVS were delivered as powders and $\mathrm{p}-\mathrm{DADMAC}$ as a $20 \mathrm{wt} \%$ concentrate.

Pulps

Dried industrial elemental chlorine free (ECF) bleached birch kraft pulp was used as a reference pulp (also denoted as normal pulp). The "hemi-poor pulp" was prepared by

Lyytikäinen et al. (2011). "Hemicellulose, charge, retention," BioResources 6(1), 219-231. 220 
subjecting the dried unrefined reference pulp to alkaline extraction $\left(1.0 \mathrm{M} \mathrm{NaOH}, 25{ }^{\circ} \mathrm{C}\right.$, $2 \mathrm{~h})$. The extraction was carried out at the VTT Technical Research Centre of Finland. After extraction, the pulp was separated from the extraction liquor and centrifuged to reach a dry matter content of ca. $35 \%$. The chemical compositions of the pulps are given in Table 1.

Table 1. Chemical Compositions of the Hardwood Kraft Pulps

\begin{tabular}{|l|c|c|}
\hline Component & Reference & Hemi-poor \\
\hline Cellulose & 74.8 & 85.3 \\
\hline Xylan & 23.6 & 13.0 \\
\hline Glucomannan & 1.1 & 1.1 \\
\hline Lignin & 0.4 & $<0.4$ \\
\hline
\end{tabular}

Wet-end additives

The filler used in the study was Intracarb ${ }^{\mathrm{TM}} 60$, provided by Imerys. This medium coarseness ground calcium carbonate (GCC) has a steep particle size distribution, and it contains a low amount of dispersant. According to the manufacturer about $60 \%$ of the filler particles are smaller than $2 \mu \mathrm{m}$ in diameter.

The retention polymer used in this study was cationic polyacrylamide (C-PAM, Fennopol K3400R, Kemira).

\section{Methods}

Pulp characterization

The polyelectrolyte adsorption technique was selected for the determination of fiber charge characteristics because with this technique both total and surface charge of the fibers can be evaluated. The experimental procedure is widely used and well described in several references (Wågberg et al. 1985, 1989; Laine et al. 1996; Fardim et al. 2002; Horvath et al. 2006)

Prior to the polyelectrolyte adsorption experiments, the pulp samples were diluted with deionized water to a consistency of about $10 \mathrm{~g} / \mathrm{L}$. The $\mathrm{pH}$ of the pulp suspensions was then adjusted to about 2 in order to remove any sorbed metal ions and to convert the carboxyl groups to their H-forms. The pulp suspension was kept in these conditions for 15 minutes and then washed with deionized water until the conductivity of the filtrate was under $5 \mu \mathrm{S} / \mathrm{cm}$ and the $\mathrm{pH}$ was about 5 . After this, the pulp carboxyl groups were converted into their Na-form through treatment with $0.001 \mathrm{M} \mathrm{NaHCO}_{3}(10$ minutes in 25 ${ }^{\circ} \mathrm{C}$ ) and an addition of $\mathrm{NaOH}$ in order to adjust the $\mathrm{pH}$ of the suspension to 9. These conditions were kept for 30 minutes, after which the pulp suspension was again washed until the filtrate had a conductivity of about $5 \mu \mathrm{S} / \mathrm{cm}$ and $\mathrm{pH}$ of about 7 . Finally the pulp suspension was diluted with deionized water to a consistency of $5 \mathrm{~g} / \mathrm{l}$.

For polyelectrolyte adsorption, $0.5 \mathrm{~g}$ of o.d. pulp sample in its Na-form and 100 $\mathrm{mL}$ of cationic polyelectrolyte solution was placed into the beaker. Polybrene with a charge density of $5.35 \cdot 10^{-3} \mathrm{eq} / \mathrm{g}$ and molecular weight of $8,000 \mathrm{~g} / \mathrm{mol}$ was used for determining the total charge, and p-DADMAC with a charge density of $6.19 \cdot 10^{-3} \mathrm{eq} / \mathrm{g}$ and molecular weight of 200,000 to $350,000 \mathrm{~g} / \mathrm{mol}$ for determining the surface charge. At least five experiments with varying polyelectrolyte concentrations were performed in order to build the adsorption isotherms. After 60 minutes equilibration, the excess 
polyelectrolyte was back titrated with 0.0025 N KPVS solution using a Mütek PCD 03 streaming current detector for the endpoint determination. All adsorption experiments were performed at room temperature and $\mathrm{pH} 8$.

The water retention value (WRV) of the pulps was determined according to ISO 23714:2007. The fiber coarseness and width were determined by fiber analysis with a Kajaani FS 300 instrument. Pulp carbohydrate composition was determined using high performance anion-exchange chromatography (HPAEC-PAD) following acid hydrolysis (SCAN 71:09).

\section{Retention tests and furnish properties}

A moving belt former (MBF) was used for testing the retention behavior of the two pulps. MBF is a dynamic sheet former that simulates the drainage conditions in a real paper machine through pulsating vacuum assisted water removal. More information about the operational principle of the MBF device is provided elsewhere (Paltakari and Paulapuro 2002; Räisänen et al. 1993).

The furnish used in the retention tests contained only hardwood kraft pulp and filler (GCC, $30 \%$ addition based on o.d. pulp). In addition, the cationic retention polymer, C-PAM, was injected into the MBF sheet mold automatically 10 seconds before the sheet forming. The properties of the furnishes are given in Table 2 .

Table 2. Properties of the Pulp and Filler Blends Used in MBF and RPA Trials

\begin{tabular}{|l|c|c|c|c|}
\hline & Reference & $\begin{array}{c}\text { Reference, } \\
\text { fines-free }\end{array}$ & Hemi-poor & $\begin{array}{c}\text { Hemi-poor, } \\
\text { fines-free }\end{array}$ \\
\hline Zeta potential, $\mathrm{mV}$ & -56.2 & -65.7 & -62.6 & -72.6 \\
\hline Conductivity, $\mathrm{mS} / \mathrm{cm}$ & 0.188 & 0.178 & 0.188 & 0.179 \\
\hline Cationic demand, $\mu \mathrm{eq} / \mathrm{l}$ & 43.2 & 24.7 & 30.2 & 25.7 \\
\hline $\mathrm{pH}$ & 8.6 & 8.4 & 8.5 & 8.4 \\
\hline Consistency, g/l & 4.7 & 4.6 & 4.7 & 4.4 \\
\hline
\end{tabular}

The laboratory sheets prepared with the MBF device are $0.190 \mathrm{~m} \times 0.190 \mathrm{~m}$ in their dimension. The sheets were dried in a rotary drum $\left(90^{\circ} \mathrm{C}, 3 \mathrm{~h}\right)$ and tested for their grammage (ISO 536:1995) and ash content (ISO 1762:2001).

The system zeta potential of the furnishes was measured using a Mütek SZP-06 device. The cationic demand of the filtrates passing through a 200-mesh wire was determined using a Mütek PCD 03 streaming current detector.

A retention process analyzer (RPA) equipped with a commercial wire cloth was used as an additional tool for the investigation of filler retention in the presence of CPAM. $500 \mathrm{ml}$ of the furnish (for properties, see Table 2) was transferred to a mixing vessel at rotational speed of $800 \mathrm{rpm}$. After a set time, the retention polymer (C-PAM) was dosed into the vessel and the time-recorder started. The retention phenomenon was monitored by recording the change in turbidity as a function of time. The measurement principle is described elsewhere (Saharinen 1998).

\section{Pulp fractionating}

A Dynamic Drainage Jar (DDJ) equipped with a 200-mesh wire was used for separation of fines from Valley beaten ( ${ }^{\circ}$ SR 30$)$ pulps. The fractionating was carried out 
at a consistency of about $10 \mathrm{~g} / \mathrm{L}$. The separation cycle was repeated 5 times, i.e. until the filtrate was sufficiently clear. It was determined that about $95 \%$ of the fines present in the beaten pulps could be collected by this way. The long fiber fraction resulting from the separation is denoted as "fines-free pulp".

\section{RESULTS AND DISCUSSION}

\section{Fiber Charge Properties}

The unbeaten pulps, beaten pulps, and beaten pulp fractions, i.e. fines and the corresponding long fiber fractions, were analyzed for their surface and total charge using the polyelectrolyte adsorption technique. The ${ }^{\circ} \mathrm{SR}$ values for the unbeaten pulps were 18 and 14 for the reference pulp and hemi-poor pulp, respectively. The results from the surface charge measurements are shown in Fig. 1.

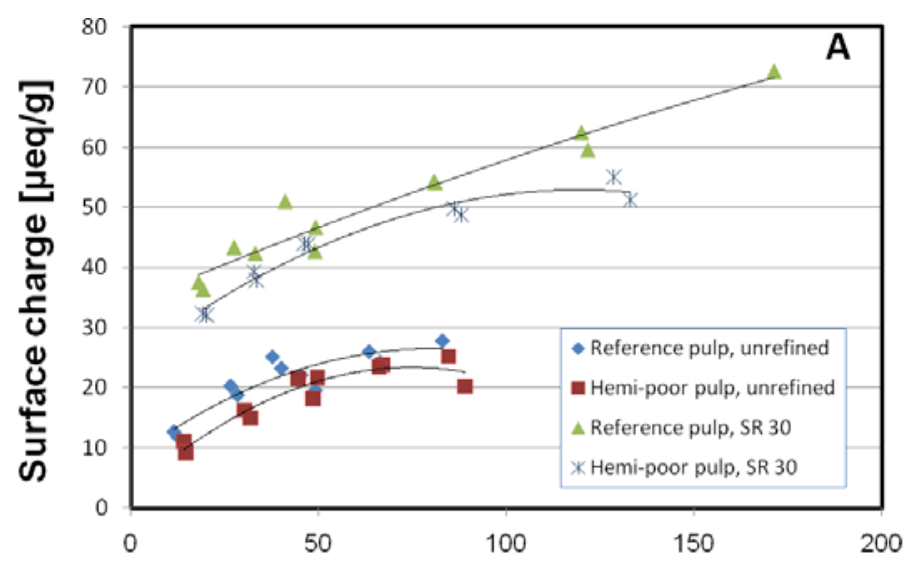

Equilibrium concentration of p-DADMAC [mg/l]

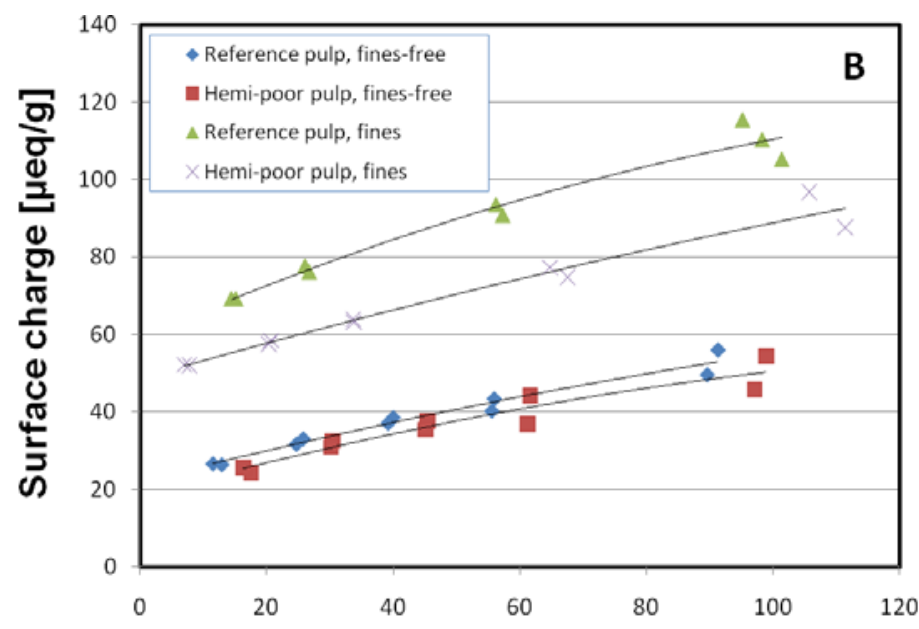

Equilibrium concentration of $\mathrm{p}$-DADMAC [mg/l]

Fig. 1. The surface charge of the unrefined and Valley refined hardwood kraft pulps (A) and the fractions of the refined pulps (B) 
According to Fig. $1 \mathrm{~A}$, the charge accessible to p-DADMAC (denoted here as surface charge) increased considerably due to refining for both pulps. This increase is mainly attributed to the increase in specific surface area of the pulp samples. Valley beating is known to simultaneously induce both internal and external fibrillation of the fibers, as well as the generation of fines (Kang and Paulapuro 2006). The opening of the fiber structure means that more carboxyl groups can be neutralized by p-DADMAC molecules.

The apparent surface charge of the hemi-poor pulp seemed to be slightly lower in comparison to the normal pulp (Fig. 1 A). Further analysis of the pulp fractions revealed that there was practically no difference in the surface charge density of the fines-free pulps. However, the surface charge of the fines fraction was significantly reduced when the hemicelluloses are removed (see Fig. 1 B). In general, the fines showed a higher surface charge than the fibers, mainly because the accessibility of the charged groups in the fines is higher than in the fibers, but also because the chemical composition may differ between the two fractions (Mosbye et al. 2002; Liimatainen et al. 2009).

It can be hypothesized that if the removal of xylan from the cell wall of dried fibers increases the fiber wall porosity and/or the surface roughness, then the adsorption of high-molecular weight polymer should increase. The adsorption of cationic polyelectrolytes is known to be influenced by the nanoporous structure of the substrate, i.e. the larger the cell wall pores, the more and the faster the cationic polyelectrolyte can penetrate into them (Wågberg and Ödberg 1989; Wågberg 2000; Alince 2002; Hubbe et al. 2007). So far, there has not been published data concerning the effect of alkaline extraction of dried and bleached fibers on fiber wall structure. However, it was recently reported for never-dried unbleached kraft pulp that the alkaline extraction of hemicelluloses produced fibers with more porous surface structure (Wan et al. 2010). On the other hand, in cases where the hemicelluloses are removed from the pulp fibers before drying, a more compact fiber wall structure may also be formed (Moss and Pere 2006).

Whereas the fiber cell wall structure has a great impact on the adsorption of highmolecular weight polyelectrolytes, it should not have any contributions to the total charge determined by the adsorption of lower-molecular weight polymer. The results from the total charge measurements are shown in Fig. 2.

According to Fig. 2 A, the total charge was virtually the same for unrefined and refined pulps. Thus, it is evident that the increase in specific surface area had no influence on the adsorption of Polybrene. This is in agreement with previous results by other authors, according to which the fiber total charge is only affected by the chemical composition of the fibers and not the physical state of the cell wall (Herrington and Petzold 1992; Bhardwaj et al. 2004).

The results shown in Fig. 2 B reveal that the hemicellulose extraction reduced the amount of charged groups both in fines free pulps and fines. The difference seems to have been somewhat larger for the fines, indicating that the hemicellulose extraction might have removed the charged groups more effectively from the fines than from the long fibers. In other words, for reference pulp the fines fraction was clearly more charged than the fiber fraction, while this difference was much smaller for hemi-poor pulp. 


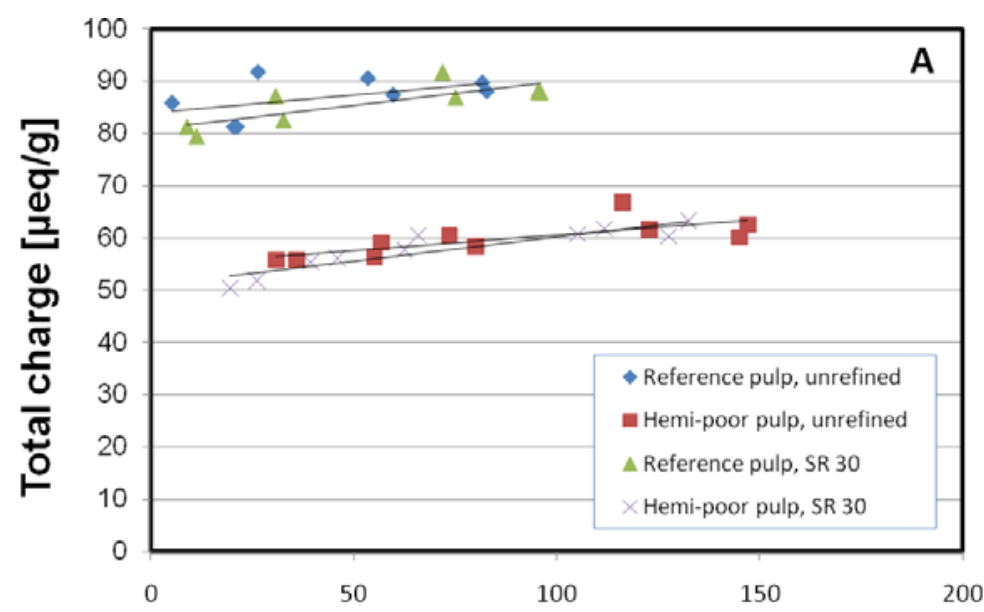

Equilibrium concentration of Polybrene [mg/l]

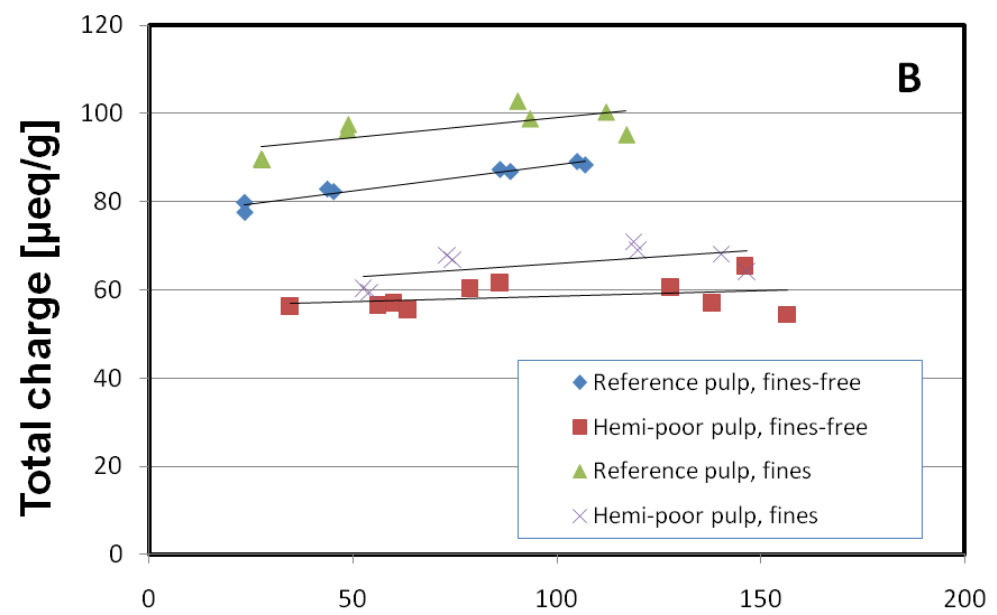

Equilibrium concentration of Polybrene [mg/l]

Fig. 2. Total charge of the unrefined and Valley refined hardwood kraft pulps $(A)$ and the fractions of the refined pulps $(B)$

The results of the total charge measurements support the hypothesis, according to which the similar apparent surface charge for the long-fiber fractions from normal and hemi-poor pulp was mainly due to the higher accessibility of charged groups in hemipoor fibers. Unfortunately, no analysis for fiber wall porosity was available at this point. However, the water retention value (WRV) and the ratio of coarseness to fiber width showed indications about the increased fiber wall porosity due to hemicellulose extraction (Table 3), i.e. the WRV value is increased and the coarseness-to-width ratio decreased due to hemicellulose extraction. 
Table 3. Properties of Unrefined, Refined, and Fines-Free Pulps. Fines Separated from Valley Refined Pulp in ${ }^{\circ}$ SR 30

\begin{tabular}{|l|c|c|c|c|c|c|}
\hline & \multicolumn{3}{|c|}{ Reference pulp } & \multicolumn{3}{c|}{ Hemi-poor pulp } \\
\hline & Unrefined & $\begin{array}{c}\text { Valley } \\
\text { refined }\end{array}$ & Fines-free & Unrefined & $\begin{array}{c}\text { Valley } \\
\text { refined }\end{array}$ & Fines-free \\
\hline WRV, g/g & 1.04 & 1.77 & 1.55 & 1.08 & 1.86 & 1.64 \\
\hline $\begin{array}{l}\text { Coarseness- } \\
\text { to-width ratio, } \\
\mathrm{g} / \mathrm{m}^{2}\end{array}$ & 6.17 & 6.07 & 4.56 & 5.85 & 5.43 & 4.33 \\
\hline
\end{tabular}

According to the WRV measurements, the water-uptake of the hemi-poor fibers was somewhat higher than that of reference fibers, in spite of the decreased anionic group content. The WRV includes all the different types of water that the fiber may hold and is thereby affected by both the ionic charges and fiber wall porosity (Salmen and Berthold 1997). Thus the higher WRV value for hemi-poor pulp might be an implication about increased fiber wall porosity.

The results from the total charge measurements are in agreement with the polysaccharide compositions of the fines-free pulps and fines (Table 4).

Table 4. Polysaccharide Compositions (\%) of the Pulp Fractions Separated from Valley Refined Pulps in ${ }^{\circ} \mathrm{SR} 30$ using DDJ-device Equipped with $76 \mu \mathrm{m}$ (200-mesh) Openings

\begin{tabular}{|l|c|c|c|c|}
\hline \multirow{2}{*}{ Component } & \multicolumn{2}{|c|}{ Normal pulp } & \multicolumn{2}{c|}{ Hemi-poor pulp } \\
\cline { 2 - 5 } & Fines-free & Fines & Fines-free & Fines \\
\hline Cellulose & 77.5 & 72.7 & 86.9 & 85.8 \\
\hline Xylan & 21.8 & 26.5 & 12.5 & 13.4 \\
\hline Glucomannan & 0.7 & 0.9 & 0.6 & 0.7 \\
\hline
\end{tabular}

As shown in Table 4, the fines from normal pulp contained more xylan than the corresponding fiber fraction ( $26.5 \%$ vs. $21.8 \%$, respectively). However, in hemi-poor pulp the xylan content was nearly similar for both fibers and fines $(12.5 \%$ vs. $13.4 \%$, respectively). The glucomannan content was low for the fractions of both pulps.

In the light of the results from the charge measurements and chemical analysis, it seems that the fines are more effectively extracted than the long fibers when bleached and dried kraft pulp is used as a starting material for the extraction. This can be an important finding with regard to the retention behavior of the extracted pulp, as it is generally known that most of the cationic papermaking additives preferentially adsorb on pulp fines.

\section{Retention tests}

The retention behavior of the hemicellulose-extracted pulp was compared with that of the reference pulp by using the Moving Belt Former (MBF) as a primary tool. Figure 3 shows the filler retention for the systems, where $30 \%$ ground calcium carbonate was included in the furnish. Cationic polyacrylamide was used as a retention aid with a fixed dosage of 0,200 , or $400 \mathrm{~g} / \mathrm{t}$. The retention tests were also carried out with fines-free pulps. 


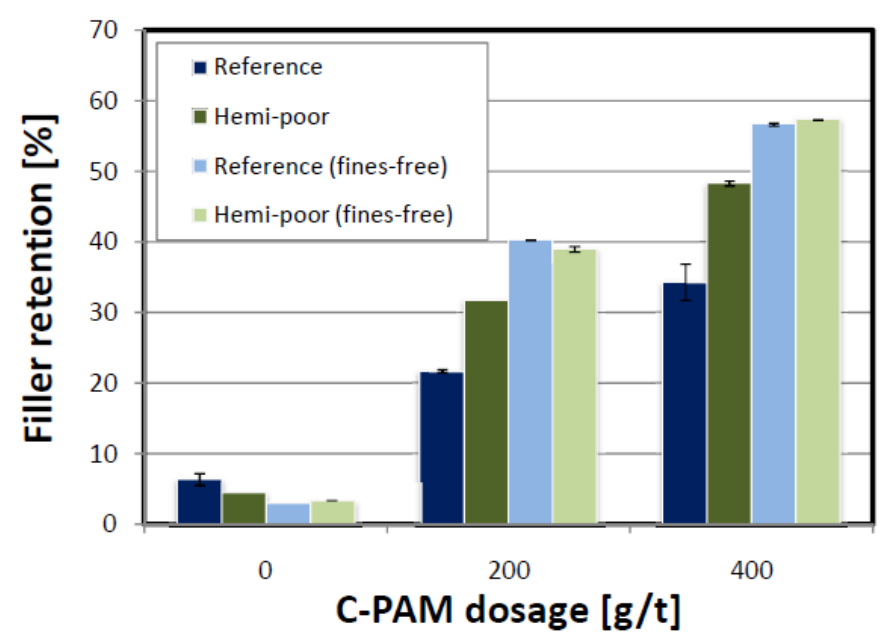

Fig. 3. Effect of hemicellulose extraction and presence of fines on filler retention with varying C-PAM dosages. $30 \%$ ground calcium carbonate was included in furnish. The injection of C-PAM took place 10 seconds before drainage. Sheets were prepared using the Moving Belt Former.

Figure 3 shows that with fixed retention aid dosage (200 or $400 \mathrm{~g} / \mathrm{t}$ ) the filler retention was notably better for hemi-poor pulp than for the reference pulp. However, when the fines were removed, the filler retention increased and there was virtually no difference between the two pulps (filler retention app. 40\% with C-PAM dosage of 200 $\mathrm{g} / \mathrm{t}$ and app. 57\% with C-PAM dosage of $400 \mathrm{~g} / \mathrm{t}$ ). A possible explanation for the improved filler retention of the hemi-poor pulp is that the fines with reduced charge adsorb less cationic retention aid, which is then more effectively used for retaining filler.

In the absence of the retention aid, the filler retention was relatively low, and furthermore, it was even lower for hemi-poor pulp than for normal pulp. However, when fines were removed, the filler retention seemed to decrease, and in this case it was similar to or even slightly higher for hemi-poor pulp in comparison to reference pulp. In earlier investigations, it has been shown that the quality of fines influences the adsorption of calcium carbonate fillers onto the fines surfaces and makes contributions to filler retention, both in the absence of and presence of retention polymer (Lin et al. 2007; Liimatainen et al. 2009).

A similar phenomenon as seen in Fig. 3 can also be seen in Fig. 4, where the filler retention is presented against time. The measurement was taken with the retention process analyzer (RPA). The same furnishes used in the MBF trials were also used in this investigation (see Table 2 for furnish properties). The RPA retention measurement is based on the continuous monitoring of turbidity, which also makes it possible to evaluate the shear sensitivity of the filler flocs formed.

According to Fig. 4, the maximum retention level was reached in approximately 6 seconds after the C-PAM injection, after which the shear forces started to decompose the flocs. It is well known that the filler retention is sensitive to shear, especially when a linear polyelectrolyte is used as a retention aid instead of a polymer with more branched structure (Shin et al. 1997; Lee et al. 2006). 
The maximum retention values were higher for hemi-poor pulp than for normal pulp with the investigated retention aid dosages, 200 and $400 \mathrm{~g} / \mathrm{t}$. No significant differences seem to have occurred in the shear-sensitivity of the formed flocs, as the curves are similar in their shape.

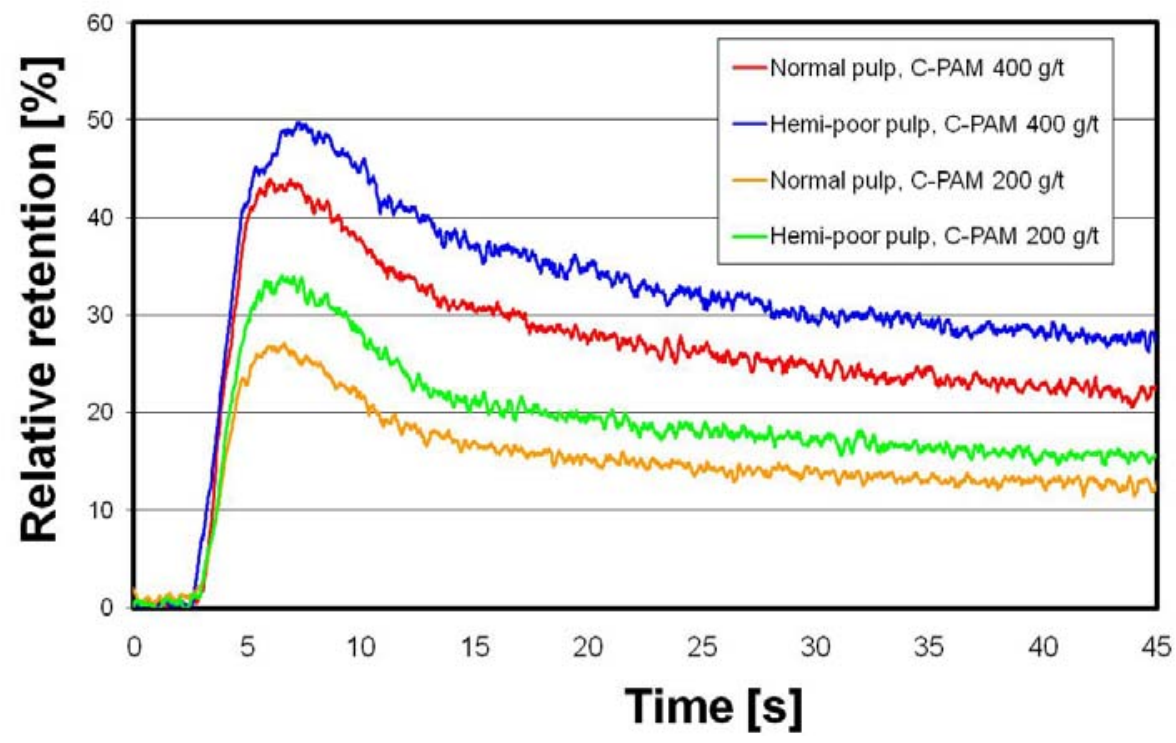

Fig. 4. The effect of hemicellulose extraction on retention of ground calcium carbonate $(30 \%$ on pulp) in presence of cationic polyacrylamide. The rotation speed in retention process analyzer was adjusted to $800 \mathrm{rpm}$. The time axis indicates time after C-PAM injection.

\section{CONCLUSIONS}

In this study, the following conclusions can be drawn related to hemicellulose extraction and its effects on fiber properties:

1. Alkaline extraction of dried and bleached kraft pulps reduces the amount of charged groups in pulps, and especially the charge density of fines.

2. For fiber fraction, the apparent surface charge, i.e. the charge accessible to highmolecular weight polymer is not reduced due to alkaline extraction. This may be caused by the increased cell wall porosity and/or surface roughness.

3. The decreased fiber charge in fines contributes positively to filler retention, allowing the cationic retention polymer to interact more effectively with the filler. The retention behavior is similar for fines-free pulps.

4. There were no differences, due to extraction of hemicellulose, in the shear-sensitivity of the flocs generated as a result of cationic polyacrylamide addition. 


\section{ACKNOWLEDGMENTS}

This work was carried out as a part of the Future Biorefinery program of ForestCluster Ltd. The authors wish to thank VTT Technical Research Centre of Finland for taking part in the testing of pulp samples. Our special thanks also go to Sari Hyvönen, M.Sc., for her invaluable help during the fiber charge measurements.

\section{REFERENCES CITED}

Al-Dajani, W. W., and Tschirner, U. (2008). "Pre-extraction of hemicelluloses and subsequent kraft pulping, Part 1: Alkaline extraction," Tappi J. 7(6), 3-8.

Alince, B. (2002). "Porosity of swollen pulp revisited," Nord. Pulp Pap. Res. J. 17(1), 71-73.

Amidon, T. E., Bolton, T. S., Francis, R. C., and Gratien, K. (2006). "Effect of hot water pre-extraction on alkaline pulping of hardwoods," 2006 TAPPI Engineering, Pulping and Environmental Conf., electronic document, TAPPI Press, Atlanta.

Bhardwaj, N. K., Duong, T. D., and Nguyen, K. L. (2004). "Pulp charge determination by different methods: Effect of beating/refining," Colloids Surf. A 236(1-3), 39-44.

Bhardwaj, N. K., Hoang, V., and Nguyen, K. L. (2007). "Effect of refining on pulp surface charge accessible to polydadmac and FTIR characteristic bands of high yield kraft fibres," Biores. Technol. 98(4), 962-966.

Chen, S.-L., Wang, S., and Lucia, L. A. (2005). "New insights into the fundamental nature of lignocellulosic fiber surface charge," J. Colloid Interface Sci. 275(2), 392397.

Fardim, P., Holmbom, B., Ivaska, A., Karhu, J., Mortha, G., and Laine, J. (2002). "Critical comparison and validation of methods for determination of anionic groups in pulp fibres," Nord. Pulp Pap. Res. J. 17(3), 346-351.

Fuhrmann, A., and Krogerus, B. (2009). "Xylan from bleached hardwood pulp - New opportunities," TAPPI Engineering, Pulping and Environmental Conf., electronic document, TAPPI Press, Atlanta.

Herrington, T. M., and Petzold, J. C. (1992). "An investigation into the nature of charge on the surface of papermaking wood pulps," Colloids Surf. 64(2), 97-108.

Horvath, E., Lindström, T., and Laine, J. (2006). "On the indirect polyelectrolyte titration of cellulosic fibers. Conditions for charge stoichiometry and comparison with ESCA," Langmuir 22(2), 824-830.

Hubbe, M. A., Rojas, O. J., Lucia, L. A., and Jung, T. M. (2007). "Consequences of the nanoporosity of cellulosic fibers on their streaming potential and their interactions with cationic polyelectrolytes," Cellulose 14(6), 655-671.

Kang, T., and Paulapuro, H. (2006), "Effect of external fibrillation on paper strength," Pulp Pap. Can. 107(7-8), 51-54.

Kautto, J., Saukkonen, E., and Henricson, K. (2010). "Digestibility and papermaking properties of prehydrolyzed softwood chips," BioResources 5(4), 2502-2519. 
Laine, J., Buchert, J., Viikari, L., and Stenius, P. (1996). "Characterization of unbleached kraft pulps by enzymatic treatment, potentiometric titration and polyelectrolyte adsorption," Holzforschung 50(3), 208-214.

Lee, H.-L., Youn, H-J., and Lee, K-H. (2006). "Effects of the size distribution of preflocculated GCC on the physical properties of paper," $3^{\text {rd }}$ International Symposium on Emerging Technologies of Pulping and Papermaking, South China Univ. of Technol. Press, China, 472-477.

Liimatainen, H., Haapala, A., and Niinimäki, J. (2009). "Retention of PCC and GCC fillers on chemical pulp fines surfaces," Tappi J. 8(9), 38-42.

Lin, T., Yin, X., Retulainen, E., and Nazhad, M. M. (2007). "Effect of chemical pulp fines on filler retention and paper properties," Appita J. 60(6), 469-473.

Mao, H., Genco, J. M., van Heiningen, A., Zou, H., Luo, J., and Pendse, H. (2008). "Technical economic evaluation of a northern hardwood biorefinery using the "nearneutral" hemicellulose pre-extraction process," 2008 Engineering, Pulping and Environmental Conf., electronic document, TAPPI Press, Atlanta.

Mosbye, J., Moe, S., and Laine, J. (2002). "The charge and chemical composition of fines in mechanical pulp," Nord. Pulp Pap. Res. J. 17(3), 352-356.

Moss, P. A. and Pere, J. (2006). "Microscopical study on the effects of partial removal of xylan on the swelling properties of birch kraft pulp fibres," Nord. Pulp Pap. Res. J. 21(1), 8-12.

Paltakari, J., and Paulapuro, H. (2002). "Moving belt former (MBF) - a versatile laboratory equipment for forming studies," $52^{\text {nd }}$ Canadian Chemical Engineering Conference, Canada, $12 \mathrm{pp}$.

Räisänen, K. O., Karrila, S., and Paulapuro, H. (1993). "Wire section simulation with the moving belt drainage tester," TAPPI 1993 Papermakers Conference, Book 1, TAPPI Press, Atlanta, 103-113.

Saharinen, E. (1998). "Filler retention dynamics with different retention aid systems," $51^{\text {st }}$ Annual Meeting, Association Technique de l'Indsturie Papetiere, Paris, 1998, 9 $\mathrm{pp}$.

Salmen, L., and Berthold, J. (1997). "The swelling ability of pulp fibres", In: Fundamentals of Papermaking Materials $-11^{\text {th }}$ Fundamental Res. Symposium, Vol 2, Fundamental Research Committee and Pira International, Leatherhead, 683-701.

Shin, J.-H., Han, S. H., Sohn, C., Ow, S. K., and Mah, S. (1997). "Highly branched cationic polyelectrolytes: filler flocculation," Tappi J. 80(11), 179-185.

Sjöström, E. (1989). "The origin of charge on cellulosic fibers," Nord. Pulp. Pap. Res. J. 4(2), 90-93.

Talja, R., Fuhrmann, A., Krogerus, B., and Vähä-Nissi, M. (2009). "Hemicelluloses from biomass to applications," The 7th Biennial Johan Gullichsen Colloquium, Finnish Paper Engineers' Association, Helsinki, 77-84.

Torgnysdotter, A. and Wågberg, L. (2003). "Study of the joint strength between regenerated cellulose fibres and its influence on the sheet strength," Nord. Pulp Pap. Res. J. 18(4), 455-459.

Vakkilainen, E. (1999). "Chemical recovery," In: Chemical Pulping, J. Gullichsen, and C.-J. Fogelholm (eds.), Fapet Oy, Papermaking Sci. Technol. Ser. 6B, Ch. 11, B7B34. 
van Heiningen, A. R. P. (2007). "Converting a kraft pulp mill into an integrated forest products biorefinery," TAPPSA J. (May), 21-28.

Wan, J. Q., Yang, Y., and Xiao, Q. (2010). "Effects of hemicellulose removal on cellulose fiber structure and recycling characteristics of eucalyptus pulp," Biores. Technol. 101(12), 4577-4583.

Wågberg, L. (2000). "Polyelectrolyte adsorption onto cellulose fibres - A review," Nord. Pulp. Pap. Res. J. 15(5), 586-597.

Wågberg, L., and Annergren, G. (1997). "Physicochemical characterization of papermaking fibres," In: Fundamentals of Papermaking Materials $-11^{\text {th }}$

Fundamental Res. Symp., Vol. 1, Fundamental Research Committee and Pira International, Leatherhead, 1-82.

Wågberg, L., Winter, L., and Lindström, T. (1985). “Determination of ion-exchange capacity of carboxymethylated cellulose fibers using colloid and conductometric titrations," In: Papermaking Raw Materials, V. Punton (ed.), Mech. Eng. Publ. Ltd., London, 917-923.

Wågberg, L., Ödberg, L., and Glad-Nordmark, G. (1989). "Charge determination of porous substrates by polyelectrolyte adsorption, Part 1. Carboxymethylated, bleached cellulosic fibers," Nord. Pulp Pap. Res. J. 4(2), 71-76.

Wågberg, L., and Ödberg, L. (1989). "Polymer adsorption on cellulosic fibers," Nord. Pulp Pap. Res. J. 4(2), 135-140.

Yoon, S.-H., Macewan, K., and van Heiningen, A. (2008). "Hot-water pre-extraction from loblolly pine (Pinus taeda) in an integrated forest products biorefinery," Tappi J. 7(6), 27-31.

Yoon, S.-H., and van Heiningen, A. (2008). "Kraft pulping and papermaking properties of hot-water pre-extracted loblolly pine in an integrated forest products biorefinery," Tappi J. 7(7), 22-27.

Article submitted: October 29, 2010; Peer review completed: November 30, 2010; Revised version received and accepted: December 1, 2010; Published: December 2, 2010; Some clarifications added to Experimental: January 15, 2011. 